\title{
A internalização da variável ambiental nas indústrias do \\ Paraná (1970 a 2006): uma análise neoinstitucional da relação entre política ambiental e indústria
}

\section{The Internalization of the Environmental Variable in the Industries of Paraná (1970 to 2006): a Neo-Institutional Analysis of the Relationship between Environmental Policy and Industry}

\author{
Mauro Guilherme Maidana CAPELARI* \\ Benilson BORINELLI* ${ }^{* *}$ \\ Saulo Fabiano Amâncio VIEIRA*** \\ Emersom Márcio RODRIGUES ${ }^{* * * *}$
}

\begin{abstract}
RESUMO
Este trabalho objetiva apresentar evidências para a compreensão do processo de internalização da variável ambiental nas indústrias do Estado do Paraná, a partir da relação entre indústria e política de regulação ambiental do Paraná. O período analisado foi de 1970 a 2006. A pesquisa possuiu abordagem teórica neoinstitucional e dois momentos de análise: reativo e proativo. No que tange aos procedimentos metodológicos, a pesquisa valeu-se de dados coletados em fontes documentais e entrevistas. Nos resultados obtidos, especificamente no período reativo, destacou-se a importância crescente das ações do governo como agentes exógenos de pressão ambiental. Além disso, as atividades ambientais das indústrias eram marcadas pelo uso de tecnologias de "fim de tubo". Em relação à fase proativa, destacou-se a edificação de arranjos produtivos locais que permitiram o uso parcial de tecnologias de prevenção à poluição. Concomitantemente, notou-se uma política ambiental do Estado mais receptiva a mecanismos econômicos. Entre 1970 e 2006, percebeu-se uma mudança na atuação da política ambiental paranaense, quando suas ações passam a incorporar elementos de mercado aliados a instrumentos de comando e controle. Em que pese isso, as indústrias passaram a implementar timidamente tecnologias ambientais de prevenção à poluição em detrimento de tecnologias exclusivamente de tratamento dessa poluição.
\end{abstract}

Palavras-chave: política ambiental; indústrias; Paraná.

\footnotetext{
"Mestre em Administração (UEL). Professor do Centro Universitário Filadélfia (UNIFIL). E-mail: capelari57@hotmail.com

** Doutor em Ciências Sociais (UNICAMP). Professor do Departamento de Administração da Universidade Estadual de Londrina (UEL). E-mail: bborinelli@) hotmail.com

**** Doutor em Administração (UNINOVE). Professor do Departamento de Administração da Universidade Estadual de Londrina (UEL). E-mail: saulo@uel.br

***** Mestre em Administração (UEL). Funcionário da Secretaria de Estado da Saúde do Paraná (SESA). E-mail: emersommarcio@hotmail.com
} 


\begin{abstract}
This study aimed to present evidence for understanding the process of internalization of the environmental variable in the industries of the State of Paraná, from the relationship between industry and environmental regulation policy of Parana. The studied period was from 1970 to 2006 . The research had a neo-institutional theoretical approach and two moments of analysis: reactive and proactive. Regarding the methodological procedures the research employed data collected from documentary sources and interviews. In the results obtained, specifically during the reactive period, they emphasized the growing importance of government actions as exogenous of environmental pressure. Moreover, environmental activities of industries were marked by the use of "end of pipe" technologies. Regarding the proactive phase, what stood out was the building of local productive arrangements that allowed the partial use of pollution prevention technologies. Concomitantly, there has been a state environmental policy more responsive to economic mechanisms. Thus, between 1970 and 2006, it was noticed a change in the performance of Parana's environmental policy, when its action started to incorporate market elements allied to command and control instruments. In conclusion, the industry shyly began to implement pollution preventive technologies rather than treatment technologies exclusively for such pollution.
\end{abstract}

Keywords: environmental policy; industries; Paraná.

\section{Introdução}

O termo internalização ambiental foi compreendido como a incorporação, pelas indústrias, de padrões, atitudes, práticas, ideias e/ou valores ambientais. O estudo de tal internalização é inerente ao entendimento das mobilizações de esforços e recursos para criar legislações e organizações ambientais públicas, em suma, a política ambiental em contexto subnacional. Isso se torna verdade, por um lado, se for levado em consideração o papel da política ambiental como reguladora das assimetrias do mercado, principalmente as assimetrias determinantes da degradação da natureza. Por outro lado, as indústrias tendem a direcionar suas ações ambientais por conta, sobretudo, das exigências legais praticadas pelos órgãos e legislações reguladoras, acoplados a outros agentes exógenos de pressão, tais como: organizações não governamentais, sociedade civil, mercado externo, dentre outros (HOFFMAN, 2001).

Estudos costumam caracterizar o processo de internalização ambiental nas organizações em diferentes etapas (JABBOUR; SANTOS, 2006; SOUZA, 2004; CORAZZA, 2003; SANCHES, 2000). Primordialmente, a existência de duas etapas é a mais bem caracterizada e utilizada em estudos organizacionais. Elas costumam ser intituladas de reativa e proativa (CORAZZA, 2003; SANCHES, 2000) e trazem em sua essência diferentes perspectivas organizacionais quanto ao processo de in- ternalização ambiental. A etapa reativa, além de outras características, é marcada pela renúncia das empresas em decidir acerca de como deveriam manusear as questões ambientais, deixando tais decisões serem direcionadas por forças institucionais coercitivas. A etapa proativa, dentre outras características, é balizada na busca pela implementação de estratégias ambientais para criar vantagem competitiva. As datas de desenvolvimento dessas fases variam de acordo com os estudos, entretanto, sabe-se que a ocorrência da fase reativa se inicia aproximadamente na década de 1970 e termina em meados da década de 1990, quando é iniciada a fase proativa.

Percebe-se nas entrelinhas dessas etapas de internalização a influência direta das manifestações do Estado, principalmente quando abordados os processos econômicos e políticos de centralização e descentralização da máquina pública. Assim, não é nenhum contrassenso apontar para a fase reativa de internalização ambiental das indústrias como pertencente a um contexto político de Estado centralizador e regulador, atuando com instrumentos de comando e controle. De tal modo, pode-se conduzir a fase proativa de internalização ambiental para próximo de um contexto político e econômico neoliberal de Estado, agindo com instrumentos de autorregulação.

Por essa razão, questiona-se: quais características as fases de internalização ambiental das indústrias reativa e proativa - tiveram no Paraná, quando analisadas a partir da intervenção das políticas ambientais 
do Estado? Assim, visando ao problema apresentado, o objetivo deste trabalho é compreender o processo de internalização da variável ambiental nas indústrias do Paraná e sua relação com a política ambiental do mesmo Estado. O recorte temporal foi de 1970 a 2006. O trabalho justifica-se pela falta e considerável atraso, dentro do Estado paranaense, da compilação de materiais que sintetizem o movimento ambiental nas indústrias e nas instituições estatais de meio ambiente. Portanto, o artigo procura igualar o Paraná a outros Estados como: São Paulo, Minas Gerais, Rio de Janeiro e Santa Catarina em termos de produção de conhecimento científico regional, especialmente sobre meio ambiente.

Além dessa introdução e dos resultados finais, o artigo está disposto em mais quatro outras seções: duas compreendem o aporte teórico da pesquisa; uma apresenta os procedimentos metodológicos utilizados no trabalho; e, por fim, a que desenvolve os resultados e as discussões do estudo.

\section{Estado, política ambiental e indústrias: uma abordagem neoinstitucional}

A crise ambiental, constatada dos anos 1960 em diante, desencadeou a criação de legislações, instituições e programas ambientais em muitos países. O que se passou a denominar genericamente de "política ambiental" foi uma resposta do Estado ao crescente esgotamento e contaminação dos recursos naturais, denunciados por vítimas desses fenômenos, assim como pelos movimentos ambientais, acadêmicos e consumidores.

Ao final da década de 1970, a maioria dos países industrializados e em processo de industrialização já possuía, sob diferentes formatos, suas agências ambientais. Inicialmente, pode-se partir de um conceito amplo de política ambiental, entendida como:

[...] conjunto de definições adotadas pelas autoridades, que condicionam e determinam de algum modo o comportamento das pessoas, das empresas e das próprias repartições públicas no que se refere ao uso, manejo e conservação dos recursos naturais e a ação dos serviços ambientais de que dispõe a sociedade. (BUSTAMANTE; TORRES, 1990, p. 110).
Num sentido estrito, as políticas ambientais são as que apresentam uma preocupação explícita quanto à proteção, conservação e uso dos recursos naturais e do meio ambiente. Essas políticas, expressas na legislação e na organização institucional correspondente, definem os instrumentos de intervenção do Estado na administração dos recursos e na qualidade do meio ambiente (MONOSOWSKI, 1989). Os dois conceitos retratam que, em qualquer um dos casos, a política ambiental engloba um campo extremamente amplo e complexo, o que lhe confere certas especificidades quando comparada a outras políticas.

O Estado desempenha papel fundamental e insubstituível no processo de regulação ambiental como representante do interesse público e garantidor de direitos ambientais. Para fazer valer a política ambiental, o Estado pode lançar mão de um conjunto de instrumentos que combinam ações de comando e controle, como normas e legislações, zoneamentos, licenciamentos e fiscalização, e de instrumentos econômicos, como taxas, impostos, permissões negociáveis de utilização, créditos subsidiados, isenções de impostos e outras facilidades contábeis para efeito da redução da carga fiscal (SOUZA, 2000).

No Brasil, o problema do esgotamento dos recursos naturais e sua relação com o modelo econômico vigente no país, desde o seu descobrimento, têm sido objetos de medidas regulatórias estatais mesmo antes do período republicano. Contudo, o que se poderia chamar de uma política ambiental surge apenas a partir da década de 1970. Desde então, assistiu-se à formação de uma considerável estrutura institucional do meio ambiente, com a criação da Secretaria Especial do Meio Ambiente em âmbito federal, em 1973, e de diversas agências estaduais e municipais especializadas. No campo legal, em 1981, foi aprovada a Lei 6.938, de 31 de agosto de 1981, que institui a Política Nacional do Meio Ambiente. Em 1988, foram estabelecidos os marcos gerais da atual política ambiental com os preceitos constitucionais, a exemplo da incorporação do conceito de desenvolvimento sustentável, da corresponsabilidade dos entes federativos pela qualidade ambiental e o direito de todos a um meio ambiente equilibrado.

Os anos 1990 demarcam uma importante mudança no arranjo institucional da política ambiental. O Estado deixa de ser o ator central na promoção da melhoria am- 
biental, deslocando e compartilhando responsabilidades com atores da sociedade civil e do mercado. Esse novo contexto mais complexo e inédito, com as empresas tendo um papel mais ativo na proteção ambiental, mostra-se mais adequado a uma interpretação institucionalista na medida em que esse novo comportamento estratégico ainda é mais determinado por pressões do ambiente externo (SOUZA, 2004).

O neoinstitucionalismo é introduzido na teoria organizacional no final dos anos 1960 e início dos anos 1970, fundamentando seus argumentos na noção de que as organizações são socialmente recompensadas pela legitimação ${ }^{1}$ e recursos e sobrevivem com base na aceitação de pressões institucionais coercitivas, normativas e adaptativas, implicando, desta forma, a transferência de valores contextuais, cerimoniais e simbólicos para a estrutura, estratégias e práticas da organização, gerando isomorfismo (FERNANDEZ-ALLES; VALLE-CABRERA, 2006). Essa teoria proporciona uma ruptura com padrões tradicionais de pensar a estrutura organizacional. Segundo Meyer e Rowan (1977), em sociedades modernas, as estruturas organizacionais formais possuem duas propriedades, a primeira em termos técnicos e a outra em termos institucionais. Relacionadas aos termos técnicos estão a venda ou a troca de mercadorias ou serviços objetivando a eficiência organizacional, enquanto as propriedades institucionais estão relacionadas com a elaboração de regras, às quais as organizações devem se subordinar para o alcance da legitimidade.

Para os teóricos embasados no neoinstitucionalismo, como John Meyer, Brian Rowan, Richard Scott e Lynne Zucker, a estrutura organizacional formal tende a ser moldada por reflexos de forças institucionais, incluindo mitos racionais, conhecimento legitimado através de ensino, das profissões, da opinião pública e da Lei. A ideia principal é de que as organizações estão profundamente enraizadas em ambientes sociais e políticos, em que as práticas e estruturas organizacionais são, amiúde, reflexões ou respostas às regras, crenças e convenções construídas em ambiente mais amplo. Entende-se, por isso, que as práticas organizacionais são socialmente constituídas (POWELL, 2007).
Complementarmente às explicações gerais, encontram-se modelos de análise que ajudam na aplicabilidade prática do neoinstitucionalismo. Um desses modelos é denominado de isomorfismo. Esse termo foi originalmente desenvolvido por DiMaggio e Powell (1983, p. 150), quando buscaram a resposta de por que as organizações são tão parecidas ou homogêneas. Esses autores identificam três mecanismos por meio dos quais a mudança institucional isomórfica ocorre: 1) isomorfismo coercitivo, que decorre de influências políticas e de problemas de legitimidade; 2) isomorfismo mimético, resultante de respostas-padrão às incertezas; e 3) isomorfismo normativo, que é associado à profissionalização.

Especificamente, o isomorfismo coercitivo resulta de pressões formais e informais de organizações sobre outras organizações dependentes das primeiras e, ainda, de expectativas culturais da sociedade na qual as organizações estão inseridas. Tais pressões podem ser sentidas como força, como persuasão ou como convites para a formação de coalizões. Em alguns casos, essas pressões provêm do governo na forma de legislações, fiscalizações e autuações. Em se tratando do isomorfismo mimético, percebe-se sua vinculação, sobretudo, em função da incerteza. Quando, por exemplo, as tecnologias das organizações são pouco compreendidas, quando as metas são ambíguas, ou quando o ambiente cria incertezas simbólicas, as organizações tendem a se moldar com base em outras organizações. Por fim, o isomorfismo normativo advém principalmente do processo de profissionalização, que pode ser definido como "esforço coletivo dos membros de uma ocupação para definir as condições e métodos de seu trabalho, para controlar a produção e para estabelecer uma base cognitiva de legitimação para a autonomia ocupacional", podendo ser citadas, como exemplo, práticas legitimadas dentro do processo produtivo de uma organização (DIMAGGIO; POWEL, 1983, p. 153).

Nota-se, assim, que a teoria neoinstitucional pode servir de aporte teórico para o estudo da internalização ambiental nas organizações, na medida em que a evolução da temática ambiental é entendida como pertencente a um processo socialmente constituído e analisado atra-

\footnotetext{
${ }^{1}$ Normas e procedimentos das organizações adotados devido ao processo de origem e semelhança das práticas culturais e não necessariamente porque aumentam a eficácia das tarefas a cumprir (DIMAGGIO; POWELL, 1983).
} 
vés de modelos isomórficos institucionais, do ambiente externo ao organizacional.

Nesse sentido, um dos fenômenos mais expressivos no combate à degradação ambiental nas últimas décadas tem sido a mudança de comportamento empresarial, em especial das indústrias. Como diversos estudos têm mostrado, essa transição vem acontecendo em várias etapas e as empresas respondem em tempos diferentes aos problemas ambientais (SOUZA, 2004; CORAZZA, 2003). Para Corazza (2003) e Sanches (2000), essas etapas podem ser descritas como reativa/integração pontual (aproximadamente de 1970 a meados de 1990) e proativa/integração matricial (meados de 1990 aos dias atuais).

$\mathrm{Na}$ fase reativa, entre outras práticas, as indústrias implementam algum tipo de sistema ou controle ambiental mediante forte pressão coercitiva, principalmente derivada de órgãos ambientais. Na proatividade, fase mais avançada da gestão ambiental, as indústrias tendem a adotar sistemas de gestão ambiental aprimorados, compostos por instrumentos como departamentos e pessoal especializados, ISO 14000 e outras certificações, produção mais limpa, entre outros, com o intuito de criar vantagem competitiva. Diversas pesquisas apoiadas em uma abordagem neoinstitucional vêm apontando que fatores externos, como as regulamentações estatais, a pressão da comunidade e de ONGs, as demandas de consumidores e o comportamento da concorrência são determinantes para explicar a estratégia ambiental das empresas (SOUZA, 2004; FERRAZ; MOTTA, 2002; HOFFMAN, 2001). Numa leitura neoinstitucional, é possível afirmar que essas estratégias ainda decorrem, principalmente, do isomorfismo coercitivo e mimético do ambiente institucional ao qual as organizações estão submetidas (ALPERSTEDT; QUINTELLA; SOUZA, 2010).

\section{A política ambiental no Estado do Paraná}

A história econômica do Paraná pode ser descrita pela sucessão de ciclos econômicos liderados pelos seguintes produtos, respectivamente: o ouro, o mate, a madeira e o café. Essas atividades, seguidas pela industrialização nos anos 1970, transformaram, num período de tempo relativamente curto, a paisagem do território paranaense (PADIS, 2006). A industrialização vai se estabelecer mais claramente no Estado a partir de 1970 e, com ela, novas evidências da degradação ambiental vieram a se somar às dos períodos anteriores, que seriam percebidas como objeto de políticas públicas da década de 1970 em diante. Entre os problemas ambientais mais sérios do Paraná, encontravam-se a erosão hídrica dos solos agrícolas e a poluição dos mananciais. Em períodos críticos, ocorreram conflitos pelo uso das águas em algumas de suas bacias hidrográficas. Existiram, também, problemas pontuais de poluição do ar, na região metropolitana de Curitiba, devido ao grande número de indústrias (BRASIL, 2001). Outro problema ambiental de grande proporção no Paraná foi e vem sendo a devastação das florestas. A intensa exploração dos recursos naturais durante o século XX, derivada, sobretudo, do cultivo do café e da extração de madeira, reduziu a cobertura vegetal de $83,7 \%$ para $5 \%$ (BRASIL, 2001).

O Paraná tem uma longa tradição de políticas ambientais conservacionistas. Embora com resultados pouco efetivos, já em 1907, o Estado aprovou o primeiro Código Florestal do país e criou, na década de 1950, órgãos como o Instituto de Defesa do Patrimônio Natural, o Conselho de Defesa do Patrimônio Natural e a Polícia Florestal. Uma abordagem mais recente da política ambiental no Estado do Paraná tem início nos anos 1970 e 1980 com a instalação da Administração de Recursos Hídricos - ARH (1973), da Superintendência dos Recursos Hídricos e Meio Ambiente - SUREHMA (1978) e do Instituto de Terras e Cartografia - ITC (1972). Todos esses movimentos estão em consonância com as orientações de comando e controle das políticas internacionais e nacionais do período, as quais priorizavam o controle da poluição industrial e a conservação das florestas.

A última expressiva mudança do aparato institucional do meio ambiente no Paraná ocorreu em 1992, quando foram criadas, num movimento de concentração institucional, a Secretaria de Estado do Meio Ambiente e Recursos Hídricos - SEMA, o Instituto Ambiental do Paraná - IAP - e, em 1996, a Superintendência de Desenvolvimento dos Recursos Hídricos e Saneamento Ambiental - SUDERHSA. Além dessas instituições, atuam no executivo estadual o Batalhão da Polícia Flo- 
restal - BPFLO, o Conselho Estadual do Meio Ambiente - CEMA - e o Conselho Estadual de Recursos Hídricos - CERH. Atualmente, continuam em atividade a SEMA, o IAP, o BPFLO, o CEMA e o CERH.

\section{Procedimentos metodológicos}

Esta pesquisa teve um caráter qualitativo, com a abordagem exploratório-descritiva e histórica. $\mathrm{O}$ intervalo temporal priorizado foi o de 1970 a 2006, respectivamente, início da implementação das organizações ambientais no Estado do Paraná e término da gestão do governador Roberto Requião. O período é particularmente interessante, porque foi nele que teve origem e se conformou a atual estrutura institucional do meio ambiente, assim como a atual planta industrial paranaense.

Para identificar e caracterizar as principais etapas da internalização ambiental nas indústrias paranaenses foram utilizadas, como categorias básicas de investigação, as fases reativa e proativa de internalização ambiental, para identificar as etapas, e instrumentos de comando e controle, instrumentos econômicos, tecnologias de controle da poluição, parcerias entre Estado e indústrias, certificações e movimentações industriais, para caracterizar tais etapas. A Administração de Recursos Hídricos - ARH, a Superintendência de Recursos Hídricos e Meio Ambiente - SUREHMA - e o Instituto Ambiental do Paraná - IAP - foram as organizações centrais do estudo quanto à análise da política ambiental por terem sido, em diversos momentos, as principais organizações executoras da política de controle da poluição industrial paranaense.

Os dados foram coletados por meio de análise documental e de entrevistas de 2009 a 2011, nas cidades de Londrina e Curitiba. Foram analisadas mensagens do governo, legislações, relatórios e sites institucionais, balanços contábeis, orçamentos, memoriais ligados ao meio ambiente, atas de reuniões e registros históricos, todos disponíveis em sites oficiais do governo estadual e nas bibliotecas do Instituto Paranaense de Desenvolvimento Econômico e Social - IPARDES, da SEMA, da Federação das Indústrias do Estado do Paraná - FIEP, do Serviço Social da Indústria - SESI - e do Serviço Nacional de Aprendizagem Industrial - SENAI.

Foram realizadas seis entrevistas com técnicos de carreira dos órgãos ambientais, funcionários e ex-funcionários de cargos estratégicos, como superintendentes e diretores. Uma entrevista complementar foi realizada no SENAI em Londrina. Para a apreciação dos dados, a confrontação, por meio da análise de conteúdo e triangulação, com aspectos políticos, econômicos e administrativos, permitiu categorizar os dados em duas etapas de internalização ambiental nas indústrias do Estado do Paraná, reativa e proativa. Os dados não foram submetidos a tratamentos em software. Houve, sim, tratamentos por prontuários.

\section{Fase reativa (1970 a 1995): a potencialização do estado regulador e a homogeneidade industrial coercitiva}

\begin{abstract}
Na década de 1970 a relação entre indústria e meio ambiente era de inimigo mesmo, os empresários diziam: esses caras [referindo-se a técnicos ambientais do Estado] vêm aqui, esses sonhadores querem botar o pé na minha indústria (Entrevista, ex-Superintendente da SUREHMA, 13 dez. 2010, p. 22).
\end{abstract}

Quando os fiscais autuavam as empresas, na década de 1970, elas simplesmente fechavam as portas e iam para o interior do Estado, se esconder por lá, porque os órgãos ambientais não tinham muita estrutura na época (Entrevista, ex- Coordenador do SENAI - Londrina, 25 jul. 2009, p. 15).

Esses fragmentos de entrevistas mostram o panorama parcial do início da política ambiental do Paraná em que, por um lado, os órgãos ambientais estavam no princípio de um processo de estruturação e com baixa capacidade institucional e, de outro, as indústrias se encontravam repletas de desconfianças em meio a um assunto novo. Dessa forma, a política ambiental paranaense foi direcionada para aspectos de comando e controle, colocados em práticas, efetivamente, na década de 1980. Também nessa década, o aumento no número de legislações, a concepção de programas fiscalizatórios, as 
primeiras autuações e características de parcerias entre o órgão ambiental e as indústrias foram percebidos.

O âmbito legal da política ambiental começa a ser construído no decorrer da década de 1970, apesar de serem encontradas legislações importantes antes desse período. Devido a isso, é possível visualizar um salto quantitativo bastante significativo na promulgação de leis da mesma pasta (Figura 1). Dentre essas leis, a suma maioria pertence à chamada agenda verde, ou seja, foram promulgadas pela preocupação com as florestas, matas ciliares e uso irracional da madeira. Uma segunda preocupação das legislações nessa época eram as bacias hidrográficas do Estado, o que proporcionou a promulgação de algumas legislações da agenda azul. ${ }^{2}$

O entendimento da predominância da agenda verde e da azul no domínio legal se dá por dois motivos principais. O primeiro motivo é a característica econômica do Paraná, onde as principais indústrias tinham propriedades de baixa tecnologia na década de 1970 e baixa/média tecnologia em 1980. Para o IPARDES (1993), a década de 1970 é caracterizada por um número bastante elevado de indústrias alimentícias $(32,46 \%)$, madeireiras $(22,74 \%)$ e de transformação mineral (15,16\%). Na década de 1980 , os três gêneros industriais continuaram predominando, contudo, acompanhados da indústria mecânica $(6,17 \%)$. Via de regra, o desenvolvimento de indústrias de baixa/ média tecnologia do setor primário tende a agredir, de forma mais incisiva, os recursos ambientais. O segundo motivo, que corrobora o alto número de leis da agenda azul no Paraná, pode ser devido à questão da necessidade industrial. As entrevistas apontaram que a maioria das indústrias que inicia um processo de instalação em determinada região tem como principal fator incentivador a facilidade em utilizar uma bacia hidrográfica. Uma bacia hidrográfica "é essencial para a captação de água que será utilizada no processo produtivo e fundamental para o escoamento dos poluentes que eram liberados" (Entrevista, ex-Diretor do IAP, 05 set. 2009, p. 26). Dessa forma, o início da industrialização tendeu a aprofundar a preocupação com os recursos hídricos do Estado, fato que pode explicar as legislações pertencentes à agenda azul das décadas de 1970 e 1980.

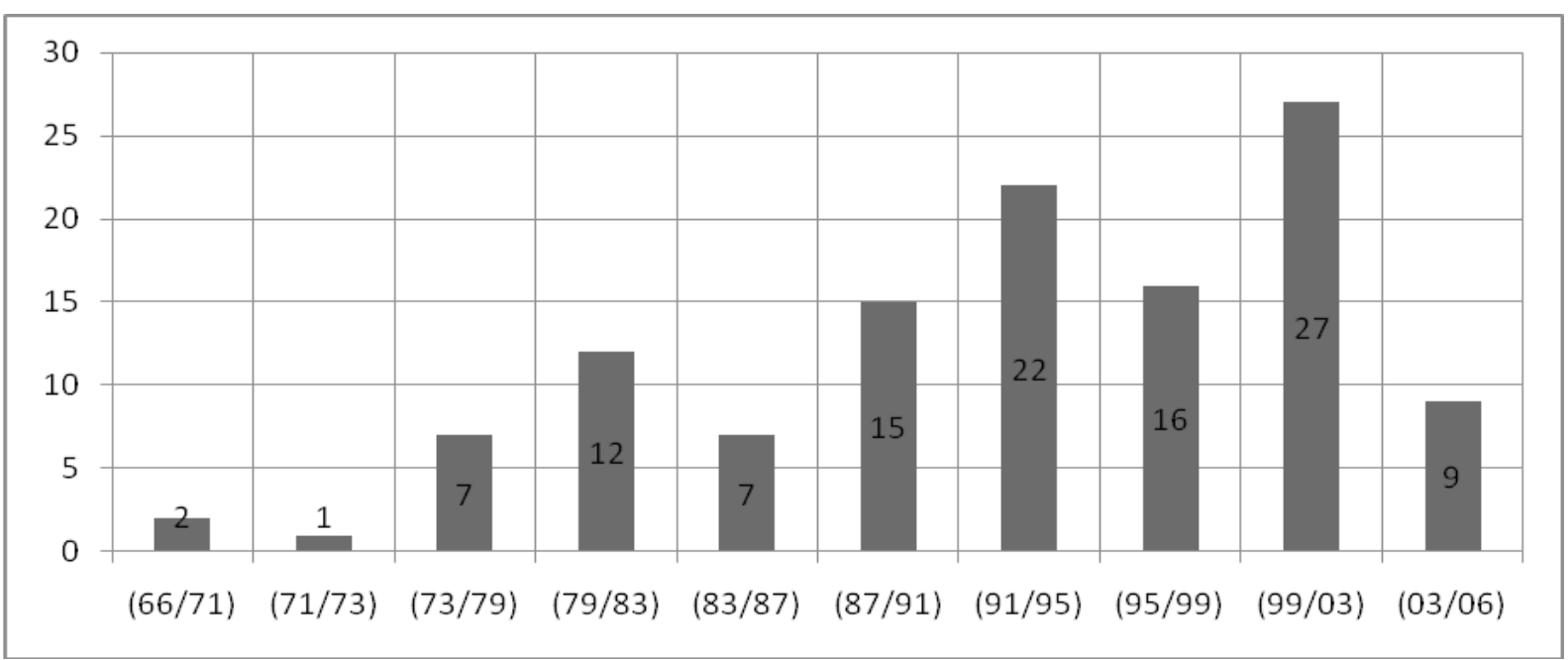

FIGURA 1 - Leis ambientais criadas pelo Estado entre 1966 e 2006.

FONTE: Borinelli (2010)

\footnotetext{
${ }^{2}$ Agendas azul, verde e marrom são entendidas como conjunto de temas a serem considerados na gestão do meio ambiente e que estão presentes na legislação ambiental brasileira. A agenda azul é específica para a gestão dos recursos hídricos, a verde enfatiza a gestão de áreas protegidas, conservação da biodiversidade e recursos genéticos. A agenda marrom tem foco na gestão do meio urbano, abrangendo aspectos como poluição atmosférica, saneamento e gerenciamento de resíduos industriais (TRIGUEIRO, 2008).
} 
Em detrimento da melhora no aparato legislativo da política ambiental, a década de 1970 ainda marcou a baixa capacidade da ARH, primeiro órgão de meio ambiente do Paraná. A princípio, o repasse de recursos do Tesouro Estadual foi bastante acanhado. Nos períodos de 1963, 1970 e 1977, os investimentos do Estado variaram, respectivamente, entre 0,$05 ; 0,08$ e $1,88 \%$ do total das verbas repassadas para o que eles chamaram de níveis administrativos. O nível administrativo "Recursos Naturais", portanto, foi o nível com pior investimento estatal nos anos referidos (IPARDES, 1980). Outro fator demarcador de fraqueza da autarquia ambiental foi o número relativamente baixo de funcionários, 160 técnicos no total (SEIN, 1979). Isso sugeriu a pouca disponibilidade em se promover concursos públicos para o meio ambiente, mesmo porque "a entidade não tinha nem cargos para serem ocupados, porque os salários eram baixíssimos [...] ninguém se interessava, naquela época, em ser superintendente da ARH [...] politicamente era muito irrelevante, financeiramente não interessava" (Entrevista, ex-funcionário ARH, SUREHMA e IAP, 14 dez. 2011).

A relação entre política ambiental e indústria paranaense, nessa década inicial, foi bastante delicada. Ao mesmo tempo em que a autarquia de meio ambiente procurava mapear e conhecer os reais danos ambientais causados pelas indústrias, estas buscavam retardar o diagnóstico final da poluição existente no Paraná e na sua propriedade. Atitudes como omissão de informações, postergação de prazos, articulações políticas, pressões na receptividade, dentre outras, formaram algumas características industriais que dificultaram a implementação de políticas de comando e controle mais severas. Ainda foram percebidas ações egocêntricas por parte dos industriais, visto que suas preocupações na inserção de tecnologias ambientais residiam na possibilidade de retração dos lucros, no aumento dos gastos e na perda da eficiência industrial. Com relação às tecnologias ambientais, as entrevistas apontaram para, quando muito, a instalação de decantadores primários responsáveis por captar sólidos grosseiros do efluente.

Constituída em 1978 para o lugar da ARH, a SUREHMA, que, na década de 1970, tinha uma estrutura precária, cujas fiscalizações eram difíceis e que quase não ocorriam por falta de funcionários e de investimen- tos governamentais, passou na década de 1980 a ocupar destaque internacional, ganhando prêmios e respeito, principalmente perante as indústrias. Essa melhora da capacidade do órgão se apresentou, sobretudo, no aumento do número de funcionários, com contratações em massa nos períodos de 1980, 1984 e 1988, chegando a alcançar 332 técnicos em 1987; na profissionalização dos agentes fiscais, principalmente através de parcerias de pós-graduação e cursos com instituições do exterior, como a GTZ da Alemanha, a JICA do Japão e a IHE da Holanda; na melhora da estrutura física, como laboratórios, equipamentos de campo e automóveis; na representatividade dos agentes fiscais no cenário nacional, como a Associação Brasileira de Entidades Estaduais de Meio Ambiente - ABEMA, que ajudou a sedimentar a política nacional de meio ambiente e, por consequência, de algumas resoluções do Comitê Nacional de Meio Ambiente-CONAMA(SUREHMA, 1990; ABEMA, 1993).

Atrelado a esse contexto de potencialização da capacidade institucional do órgão ambiental e ao período de redemocratização do país, o modelo de fiscalização empregado pelos superintendentes da SUREHMA, na década de 1980, esteve muito próximo de uma "fiscalização parceira". Esse tipo de fiscalização foi caracterizado como uma tentativa de aproximação e de relacionamento mais colaborativo entre o órgão ambiental do Paraná e as indústrias. As informações das entrevistas apontam que na época a intenção dos agentes fiscalizadores era compreender a situação dos empresários e pesquisar tecnologias ou maneiras de sanar o problema ambiental que a indústria vinha causando (Entrevista, ex-Superintendente da SUREHMA, 13 dez. 2010). Existia, portanto, certa preocupação da SUREHMA em diminuir os problemas ambientais conscientizando o empresariado da importância de se preservar o meio ambiente e ainda galgar ganhos financeiros com isso. Esses ganhos financeiros aparecem como argumento principal nas entrevistas, visto que, para os agentes fiscalizadores da SUREHMA, a poluição sempre foi encarada como perda de dinheiro e ratificadora da baixa eficiência processual. Nota-se, dessa forma, que a ideia principal do órgão ambiental era procurar tecnologias ambientais que estivessem atreladas a ganhos de eficiência, na medida em que economizassem em matéria-prima e energia. Essa visão, para os 
entrevistados, sempre foi e ainda é a melhor maneira de preservar os recursos naturais.

[...] O maior poluidor do frigorífico era o sangue. Então vamos (técnicos ambientais) ver o que nós podemos fazer com esse sangue. Começamos a pesquisar, ligar pra uma empresa, pra outra. Aí descobrimos os digestores de sangue. Com o digestor de sangue, às vezes, ele (empresário) já pagava uma grande parte dos funcionários, com o lucro que ele tinha [...] aí passamos a ver a gordura que ele jogava no rio. Eu disse: vamos fazer uma caixa aqui pra remover essa gordura, para na verdade você vender ela para uma pessoa que vai fabricar sabão, um ácido graxo, um óleo, uma oleína [...] e passou (sic) realmente as indústrias, nesse caso um frigorífico, mais os curtumes, os laticínios, a investirem, não basicamente num sistema de controle de poluição, mas num sistema de reaproveitamento de resíduos, e com isso a gente obtinha aí sessenta, setenta por cento de melhoria na qualidade para o rio, o ar, os funcionários e para a comunidade que estava no local [...] (Entrevista, ex-Superintendente da SUREHMA, 13 dez. 2010, p. 32).

A fiscalização parceira era uma fiscalização com planejamento, diálogo, institucionalização da ideia ambiental na indústria. Apenas em último caso, quando a indústria não seguia os padrões determinados, é que se atuava no campo da coerção e da multa. O modelo de "fiscalização parceira", utilizado durante a década de 1980, não significou uma fiscalização menos enérgica ou com menor poder de multa. Tanto foi verdade que, comparando-se os anos de 1975 a 1978 e meados da década de 1980 e início de 1990, percebeu-se a ocorrência de aumento nos números de fiscalização, autos de infração e no licenciamento de atividades poluidoras no Estado. Esses aumentos atingiram a porcentagem de $300 \%$, no primeiro caso, e de $800 \%$, no licenciamento, chegando ao total de 9.700 e 4.176 , respectivamente. Em relação ao número de autuações, entre 1986 e 1990, foram emitidas mais de onze mil, número significativo comparado ao da década anterior (ARQUIVO PÚBLICO DO PARANÁ, 2011; SEIN, 1979; SUREHMA, 1979; ABEMA, 1993; MMA, 2001; IAP, 2010).

No tocante à indústria e às tecnologias utilizadas para o manejo do meio ambiente, percebeu-se que a década de 1980 foi de preocupação em recuperar os ex- cedentes industriais, liberando para a natureza o mínimo de resíduos possível. Assim, as técnicas incorporadas pelas indústrias do Paraná eram de final de tubo ou end of pipe, tratamentos de efluentes, retorno ao processo e outras que diminuíam ou retardavam a evasão de poluentes para a natureza, sendo estas as principais medidas de contenção à poluição. A FIEP demonstra prioridade em utilizar essas tecnologias quando incorpora em suas funções a Escola Técnica de Saneamento e Meio Ambiente ligada ao Centro de Tecnologia em Saneamento Básico e Ambiental - CETSAM, com a prerrogativa de análise e tratamento de efluentes líquidos, sólidos e de chaminés, nas indústrias do Paraná (FIEP, 2007; Entrevista, ex-Diretor do IAP, 05 set. 2009; Entrevista, ex-Coordenador do SENAI - Londrina, 25 jul. 2009).

Até mesmo em períodos mais recentes, como em 1994, pôde-se perceber a predominância dessas características tecnológicas ambientais, quando analisados os motivos pelos quais as indústrias paranaenses foram premiadas. Exemplos disso são: a empresa Itambé, de Campo Largo, que utilizava procedimentos como sistema de coprocessamento, eliminando a poluição atmosférica e economizando energia no uso dos fornos, visto que neles eram usados resíduos de variáveis industriais e filtros de final de tubo; a Paraná Refrigerantes, de Curitiba, implementou um inovador sistema de tratamento de efluentes, além da Volvo, sediada também em Curitiba, que trouxe normas ecológicas extremamente rigorosas da matriz sueca, desde sua chegada à Cidade Industrial de Curitiba em 1970, tentando diminuir sua poluição e reaproveitando $84 \%$ do lixo gerado na unidade (EXPRESSÃO ECOLOGIA, 2002). Essas tecnologias objetivavam o tratamento e o reuso de excedentes industriais "sem o aperfeiçoamento de processos de fabricação" (Entrevista, ex-Superintendente do IAP e da SEMA, 10 dez. 2010, p. 22), fazendo com que a atividade organizacional interna permanecesse com os mesmos procedimentos, gerando as mesmas quantidades de excedentes; entretanto, esses excedentes voltavam a ser utilizados ou então eram vendidos como matéria-prima para outras indústrias.

A fase reativa do processo de internalização ambiental nas indústrias paranaenses foi marcada, portanto, pelo isomorfismo coercitivo da ARH e da SUREHMA. Na década de 1970, a coerção ambiental foi pouco desenvolvida devido à baixa capacidade institucional do órgão 
de meio ambiente, atrelada a atitudes procrastinadas dos industriais paranaenses. A partir da década de 1980, com a conquista de melhoras na capacidade da SUREHMA, a política de comando e controle do Estado ganha força, aumenta a quantidade de indústrias licenciadas, fiscalizadas e autuadas. Apesar de essas características se apresentarem com maior clareza, o instrumento de comando e controle da década de 1980 teve a intenção principal de conscientização e parceria com as indústrias. A proposta foi ajudar os industriais a encontrarem tecnologias ambientais que resolvessem suas poluições e que, ao mesmo tempo, lhe dessem garantia de retorno financeiro. As indústrias paranaenses, quanto à implementação de tecnologias, se apresentavam inseridas em processos tecnológicos de reuso e de final de tubo, principalmente porque os setores industriais predominantes eram de baixa tecnologia. Foi esse quadro, portanto, que orientou e produziu as primeiras ações ambientais das indústrias paranaenses, levando as empresas ao alcance da legitimidade e de práticas ambientais que tenderam à homogeneidade.

\section{Fase proativa (1995 a 2006): o declínio do estado regulador e a homogeneidade industrial mimética}

Com a criação do Instituto Ambiental do Paraná - IAP, em 1992, no lugar da SUREHMA, juntamente com a eleição do Governo de Jaime Lerner (PFL), características neoliberais de política e gestão passaram a vigorar na agenda da política ambiental do Paraná. ${ }^{3}$ Com isso, a capacidade institucional da autarquia de meio ambiente foi reprimida, fazendo com que o instrumento de comando e controle da autarquia cedesse espaço para instrumentos econômicos. Esse quadro implicou o aumento no número de indústrias, transferência de responsabilidades ambientais para as próprias indústrias (autorregulação) e redução da importância do órgão de meio ambiente. Em consequência disso, as indústrias dão início à necessária busca por legitimidade ambiental no mercado externo, tendo como facilitadores a formação dos arranjos produtivos locais, as parcerias com as federações industriais e as certificações ambientais. Essas características aproximam as indústrias do isomorfismo mimético neoinstitucional, demonstrando que as ações de meio ambiente do setor não mais são conduzidas pela coerção, mas pela própria necessidade de conquistar novos mercados, o que justificou práticas proativas de gestão ambiental.

A redução da capacidade do IAP foi observada a partir de quatro características. A primeira delas fez menção ao aumento da politização em cargos estratégicos dentro da autarquia ambiental. Os grupos de cargos de Direção e Assessoramento Superior - D.A.S. - estiveram presentes, em forma de crítica, na maioria das entrevistas realizadas. A implicação desse fato foi o avanço da ingerência administrativa da autarquia ambiental, visto que os cargos eram ocupados por elementos estranhos ao órgão, mas que estavam lá para gerenciá-lo. A segunda característica esteve ligada à não realização de concursos públicos para a área ambiental nesse período. Devido a isso e também à evasão de técnicos para o setor privado e para a aposentadoria, o número absoluto de funcionários do órgão ambiental foi reduzido entre 10 a 15\% (AMES; KECK, 1997; TRIBUNAL DE CONTAS DO ESTADO DO PARANÁ, 2011).

A rescisão dos convênios com órgãos internacionais como a GTZ e a JICA foi a terceira demarcação. Primordial para o encerramento das profissionalizações, cursos e treinamentos dos fiscais de meio ambiente, tal rescisão prejudicou o instrumento de coerção do IAP na medida em que os fiscais da autarquia ambiental não acompanharam os avanços tecnológicos ocorridos nos processos industriais. Esse fato fez das fiscalizações uma sala de aprendizado, pois os fiscais do IAP rece-

\footnotetext{
${ }^{3}$ Como medida de bloqueio e mitigação à crise econômica vivenciada no Brasil no final dos anos 1980, lança-se mão, ainda na candidatura à presidência de Fernando Collor de Melo, do projeto "Brasil Moderno" ou neoliberal (BALTAR, 2009). Distante da proposta de modernidade empreendida em governos anteriores, neste caso a terminologia esteve associada à dualidade entre a competitividade do país e a regulação do Estado (BALTAR, 2009). Neoliberal, portanto, significou ampliação da eficiência e eficácia da administração pública, das instituições políticas, dos partidos, das políticas públicas e, paralelamente, alterações na face reguladora do Estado na economia. Esteve pautado pelas diretrizes estabelecidas pelo Consenso de Washington, com o objetivo principal de ajustar a economia devedora brasileira às necessidades das economias credoras norte-americana e europeia.
} 
biam aulas do setor ambiental da indústria. "Eu vi um caso de um jovem de uma empresa que ele te dava aula, aquele que você fala: nossa não sei nada" (Entrevista, funcionário da SUREHMA e IAP, 06 dez. 2010, p. 6). Por fim, a queda do repasse de verba do tesouro estadual para a autarquia de meio ambiente encerra os argumentos a favor de uma redução da capacidade institucional. Entre os anos de 2002 e 2008, a participação da pasta de meio ambiente nos gastos totais do Estado caiu de 1,12\% para $0,45 \%$, acompanhada de uma redução de $50 \%$ da receita do IAP vinda do Tesouro Estadual (STN, 2011; IPARDES, 2011).

Mediante o contexto apresentado, a consequente perda da qualidade do instrumento de comando e controle foi uma questão de tempo. As fiscalizações passaram a ser feitas em períodos fragmentados de dois em dois anos, sem mais o caráter sistêmico anteriormente presente. Fora desse período, o órgão só fiscalizou quando amparado por denúncias da sociedade civil ou por incumbência do Ministério Público e da Promotoria Pública. As entrevistas realizadas relatam críticas ao novo rumo das ações fiscalizatórias, principalmente por deixar na mão das empresas o ato de fiscalizar a si próprias. Em complemento, foram referidas, em entrevistas, reduções consistentes nas emissões de autos de infração às indústrias nesse período. Como apresentou a ABEMA(1993), esses números foram reduzidos a patamares mínimos já no início da década de 1990. Desse modo, tornou-se plausível a argumentação de que o direcionamento da política econômica do Estado para caminhos neoliberais reduziu a estrutura e os planos de ações referentes aos atos regulatórios do IAP, apesar de ainda estarem presentes na política ambiental paranaense na forma de promulgação de leis (Figura 1) e de emissão de licenças ambientais.

Com os instrumentos de comando e controle quase fora da pauta governamental, outros modelos de política pública ambiental se apresentaram como relevantes nesse período, sobretudo o instrumento econômico.

O BNDES já não autoriza mais nenhum financiamento se não tiver uma licença de instalação do IAP, a parte florestal também, se o empresário não tiver a parte de preservação permanente, a área de reserva legal, ele não consegue uma licença e muito menos um financiamento
(Entrevista, ex-Superintendente da SUREHMA, 13 dez. 2010, p. 14).

A pesquisa de Zaparolli e Câmara (2009) também abordou esse instrumento dentro das indústrias do $\mathrm{Pa}$ raná, especificamente no polo moveleiro da região norte do Estado. Os dados desse trabalho concluíram que a redução da multa ambiental num valor de $99 \%$, tendo em contrapartida o comprometimento da indústria em instalar tecnologias que a deixem em conformidade com o código ambiental vigente, foi um procedimento que trouxe benefícios tanto para os empresários como para a sociedade e o meio ambiente. Outro exemplo ilustrativo desse mesmo mecanismo foi a isenção de impostos territoriais para multinacionais que se instalassem no Paraná mediante apresentação de plano de gestão ambiental. Esses incentivos fiscais transformaram a Região Metropolitana de Curitiba em um dos mais importantes polos automotivos do país, além de aumentar o número absoluto de indústrias no Estado em quase $50 \%$, ao passar de 18,4 mil para 27,45 mil estabelecimentos entre 1990 e 2000 (FIEP, 2009).

A abertura econômica ao mercado externo, primeiro marco debatedor, foi determinante nas mudanças tecnológicas ambientais e no modelo de atuação das indústrias, principalmente por meio de suas atitudes proativas. Tendência observada em todo o país, a abertura econômica do mercado brasileiro conduziu o desempenho das indústrias paranaenses para próximo de transformações em sua estrutura produtiva. Em decorrência desse contexto, houve a mudança na base tecnológica do Estado, fator que possibilitou o início da implementação de tecnologias ambientais mais consistentes e desvinculadas das técnicas de final de tubo. Migliorini (2006) mostrou que o grupo industrial paranaense ligado à alta tecnologia saltou em representatividade de $15,1 \%$, no ano de 1985 , para $26 \%$, no ano de 1995 . Em números, a malha produtiva do grupo cresceu $130 \%$, acompanhada pelo aumento de $2.102 \%$ na capacidade instalada, entre os anos de 1985 e 2000 (NOJIMA, 2002). Setores como refino de petróleo e produção de álcool $(22,1 \%)$, bebidas e produtos alimentares $(17,9 \%)$, veículos automotores $(14,8 \%)$ e máquinas e produtos químicos $(5,5 \%)$ ajudaram na construção e na manutenção desse cenário industrial. Para o crescimento das indústrias de alta tecnologia, 
houve a perda de espaço do grupo de baixa tecnologia. Sua redução de $10 \%$ entre os anos de 1985 e 1995 foi devido a baixas no setor madeireiro, transformação de mineral não metálico e têxtil (IPARDES, 1993).

Em vista disso, expressivos aumentos de produtividade, atrelados a reduções de margens de lucros ocorridas pelo acirramento da concorrência, formaram o quadro industrial do período. A eficiência das indústrias, portanto, passou a ser sinônimo de modernização, reposição e racionalização de equipamentos e modelos produtivos já existentes (IPARDES, 2002). Dessa forma, os Arranjos Produtivos Locais - APL ${ }^{4}$ - se apresentaram como facilitadores do desenvolvimento de ações e tecnologias ambientais proativas, sobretudo nas pequenas e médias empresas paranaenses (IPARDES, 2003). A proatividade dos APL foi observada na organização das indústrias para aproveitar os resíduos sólidos e na cooperação dos empresários para eliminação das multas ambientais. Ganhos também foram percebidos na integração social da região onde os arranjos produtivos se encontram, assim como na cooperação e no aprendizado interativo (IPARDES, 2003). A título de exemplo, Demajorovic e Silva (2010) demonstram as práticas ambientais mais usuais em um estudo de caso do arranjo produtivo moveleiro de Arapongas. Os resultados mostram os avanços nos cuidados com os resíduos industriais, com a compra de matéria-prima certificada e com a redução do consumo de água e também de energia. Tais avanços são fruto, segundo a pesquisa, de exigências dos clientes nacionais e internacionais e da manutenção da imagem empresarial. O APL de Arapongas, portanto, se mostrou essencial para que as empresas superassem suas limitações de desempenho ambiental.

A questão ambiental em APL foi uma variável que ocupou cada vez mais destaque no Paraná, como exemplificado na parceria do Centro de Tecnologia da Madeira e do Mobiliário - CETMAN - junto ao SENAI-PR. A parceria rende inovações ambientais que geram menor custo de produção, como a centralização do tratamento de resíduos de pequenas empresas pelo CETMAN, diminuindo os custos de instalação de centrais de tratamento de resíduos e fornecendo orientação ambiental para as empresas (ZAPAROLLI; CÂMARA, 2009).

Além dos APL, parcerias entre indústrias e órgão ambiental foram encontradas nesse período, configurando-se como o segundo marco da proatividade industrial. Em 2004, por exemplo, o IAP e a SEMA assinaram o Programa Cooperativo de Gestão Ambiental nas Indústrias Paranaenses em conjunto com a FIEP e o SENAI-PR, propondo a união dessas entidades para intercâmbio tecnológico. Também houve acordo envolvendo FIEP, SEMA, IAP e Ministério Público visando ajudar o setor industrial a resolver pendências no cumprimento da legislação ambiental, evitando penalizações a partir de planejamento monitorado para a solução dos problemas. A Federação das Indústrias do Paraná ainda aumentou seus programas relacionados com a área de meio ambiente. O Prêmio Paraná Ambiental (1997), criado para homenagear atitudes empresariais que valorizem o meio ambiente; a Bolsa de Reciclagem (2001), com a finalidade de comercialização e doação de resíduos industriais e urbanos; e o Mecanismo de Desenvolvimento Limpo (2005), criado para otimizar o processo energético das indústrias, ilustram o aumento da preocupação do setor industrial com causas de proteção ambiental (FIEP, 2009).

Descrevendo elementos básicos de um sistema de gestão ambiental eficaz surge, em 1996, a ISO 14.001, o terceiro marco das ações proativas industriais. Em todo o Paraná, apenas 55 empresas detinham tal certificação no ano de 2009, estando 42 sediadas na Região Metropolitana de Curitiba. Além disso, essas 55 empresas foram caracterizadas por possuírem mais de 500 funcionários, ou seja, consideradas de grande porte, e também por serem criadas na própria década de 1990, o que demonstrou a preocupação ambiental mais associada a indústrias paranaenses jovens (INMETRO, 2010). Esses dados corroboram o estudo de Wachholz (2004). Esse autor reproduz no Paraná a pesquisa da International Business Environmental Barometer - IBEB, que visou analisar a perspectiva ambiental das principais lideranças empresariais da região. Os resultados encontrados apontaram

\footnotetext{
${ }^{4}$ É constituído por empresas que se organizam em redes networks e desenvolvem sistemas complexos de integração e esquemas de cooperação, solidariedade e valorização do esforço coletivo, entre si e com outros atores locais, como governo, associações empresariais, instituições de crédito, ensino e pesquisa. O resultado é o aumento da competitividade das empresas e do sistema em comparação às firmas que atuam isoladamente (IPARDES, 2003).
} 
para a comprovação de que, no Paraná, a maioria das indústrias ainda usa tecnologia de fim de tubo, uma pequena porcentagem usa a prevenção da poluição, e outra, menor ainda, começa a inserir o processo de Sistema de Gestão Ambiental. As porcentagens, respectivamente, giram em torno de $60 \%, 30 \%$ e $10 \%$.

Exemplo de ação proativa no Paraná foi o caso da Klabin-PR no ano de 1996 (Entrevista, ex-Diretor do IAP, 05 set. 2009; Entrevista, ex-Superintendente da SUREHMA, 13 dez. 2010; Entrevista, funcionário da SUREHMA e IAP, 06 dez. 2010). Indústria do ramo de papel e celulose estabelecida na cidade de Telêmaco Borba - PR e conhecida por sua extensiva poluição na bacia do rio Tibagi desde a década de 1940 (CUNHA, 1982), a Klabin-PR vinha em processo de incremento parcial de tecnologias ambientais em sua planta produtiva. Pressionada pelo órgão ambiental paranaense, até a década de 1990 a indústria incrementou pequenas melhorias no processamento interno de produção que ajudaram a aprimorar a eficiência no uso dos recursos naturais. Foram constatados, ainda, decantador primário para retirada de sólidos grosseiros do efluente, processos de reuso da lixívia negra ${ }^{5}$ como combustível para a caldeira, tratamentos de efluentes através dos seletores biológicos, tanques de aeração e decantadores secundários, além das tecnologias para a questão do mau cheiro na região. No ano de 1996, já com as exigências legais de meio ambiente sendo cumpridas, a papeleira contratou uma empresa especializada em auditoria ambiental e se tornou a primeira indústria do Paraná a desenvolver uma auditoria ambiental interna. A ideia principal dessa auditoria foi fazer com que o processo produtivo do papel gerasse a menor quantidade de poluição possível. Para isso, "foram gastos 150 milhões de dólares, onde a empresa teve que mudar seu processo industrial, porque seu processo gerava muitos resíduos e a grande tecnologia hoje é não gerar esses resíduos" (Entrevista, ex-Diretor do IAP, 05 set. 2009, p. 20).

Em complemento, a Klabin-PR, dentro da década de 1990, se transformou em uma das indústrias mais pre- miadas e certificadas pelo seu comportamento ambiental no Paraná. Talvez esteja ligado a isso seu direcionamento produtivo para o mercado externo (LOPES, 1998). Como destaque, têm-se os doze prêmios do Prêmio Expressão Ecológica ${ }^{6}$ que deixaram a empresa como a maior ganhadora da história e uma das mais importantes indústrias fomentadoras de ações ambientais no sul do País. Com relação às certificações, a empresa conquistou os selos FSC de Manejo Florestal Madeireiro, Cadeia de Custódia dos Produtos Florestais, Cadeia de Custódia de Cartões e Kraftliner, Cadeia de Custódia de Sacos Industriais, Cadeia de Custódia de Papelão Ondulado; ISO 14001:1996 relacionado ao sistema de gestão ambiental; ISO 9001 atrelado à qualidade do processo produtivo; OHSAS 180001, selo relacionado à segurança e saúde ocupacional. Goza, ainda, de títulos como o de maior recicladora de papel do Brasil e de indústria que desenvolve a conscientização ambiental dos funcionários e das comunidades onde atua através de projetos de educação ambiental (KLABIN, 2011).

O caso Klabin-PR não foi singular dentre as indústrias do Paraná. Embora em pequena quantidade, ainda existiram casos como o da Tamarana Metais, indústria do ramo de baterias sediada em Tamarana-PR, que foi uma das indústrias pioneiras na conquista da certificação série ISO 14.001 na América Latina. Em pesquisa, CETSAM (1997) aponta os ramos industriais de química, de bebida, de alimentos, de papel e celulose e de refinamento de petróleo e álcool como os de maior destaque no uso de tecnologias ambientais no Paraná. Tais ações ainda podem ser percebidas nos arranjos produtivos locais do setor moveleiro. Tudo isso demonstrou a existência de movimentações proativas das indústrias, inclusive ao darem início a uma tradição, dentro do Estado, em preservar o meio ambiente em contexto distante da coerção do órgão ambiental do Paraná.

Nota-se, portanto, que, na fase ambiental proativa, as indústrias paranaenses deram início ao uso de processos que eliminaram a produção de resíduos e poluentes, ainda que de maneira não tão incisiva. Essas tecnologias

\footnotetext{
${ }^{5} \mathrm{Na}$ indústria papeleira, o licor negro ou lixívia negra é um fluido processual produzido na saída do digestor e responsável pela cozedura da madeira para retirar componentes indesejáveis ao processo de fabricação do papel, tais como lenhina, extrativos e cinzas.

${ }^{6}$ O Prêmio Expressão Ecológica foi criado em 1993 pela Editora Expressão devido a reflexos da Conferência Mundial do Meio Ambiente no Rio de Janeiro, em 1992. Tornou-se a premiação mais importante na área de meio ambiente para a região sul do Brasil.
} 
foram descritas como "tecnologias limpas que fabricam sem gerar resíduos" (Entrevista, ex-Superintendente da SUREHMA, 13 dez. 2010, p. 13). Incentivados, principalmente, pela formação de arranjos produtivos locais, pelas certificações ambientais e pelas parcerias do órgão ambiental com a Federação da Indústria, a fase proativa apresentou elementos neoinstitucionais miméticos que ajudaram na redução de custos e no fortalecimento dos ganhos decorrentes do melhor aproveitamento dos recursos naturais. Como apenas uma pequena parcela das indústrias paranaenses aderiu a essa fase, ela pode ser considerada como de proatividade parcial, corroborando estudos desenvolvidos em outros Estados da Federação (ALPERSTEDT; QUINTELLA; SOUZA, 2010). O mimetismo encontrado ganhou fôlego devido à perda da capacidade do órgão de meio ambiente e, consequentemente, à decadência do instrumento ambiental de comando e controle, principal agente fomentador do elemento neoinstitucional coercitivo. Dessa forma, para a conquista de nichos de mercado nacional e internacional, as indústrias buscaram formas de institucionalizar suas ações na área de meio ambiente. Isso justifica o aumento dos selos verdes, das parcerias e dos APL no Estado, assim como de ações ambientais proativas das indústrias.

\section{Considerações finais}

Procurando compreender o processo de internalização da variável ambiental nas indústrias do Paraná, particularidades institucionais puderam ser encontradas nas fases reativa (1970-1995) e proativa (a partir de 1995). De maneira geral, a fase reativa ficou caracterizada pela ação coercitiva do Estado, através de instrumentos de comando e controle aplicados nas indústrias. Essa ação coercitiva esteve relacionada com o ambiente institucional ligado às indústrias, especialmente ao isomorfismo coercitivo representado pelas leis homologadas, pelas ações fiscalizatórias e pela emissão de autos de infração nas atividades poluidoras. Na década de 1980, em decorrência de política governamental específica, as ações coercitivas vieram acompanhadas de uma aproximação entre Estado e indústrias na busca pelo desenvolvimento de tecnologias ambientais, podendo-se caracterizar o ato fiscalizatório como parceiro, visto que priorizou a resolução da poluição em decorrência do simples fato de multar. Para a implementação das tecnologias ambientais na fase reativa, o ambiente coercitivo facilitou um início de homogeneidade nas tecnologias de tratamento da poluição. Essas, por sua vez, detinham o propósito de recuperar e diminuir resíduos antes de liberá-los no ambiente.

Em relação à fase proativa, a presença do ambiente institucional coercitivo ainda se faz presente, contudo, perde em importância para os instrumentos econômicos, principalmente os relacionados a parcerias e ajustes na cobrança de multas ambientais. Essa tendência é encontrada em todo o país e decorre do modelo de política e gestão neoliberal. Percebeu-se, ainda, que as indústrias paranaenses, facilitadas pelo processo de aglutinação, representado pela figura dos APL, tornaram suas tecnologias ambientais mais homogêneas e legítimas. Esses APL contribuem, por outro lado, na redução de custos e no aumento dos ganhos ambientais das indústrias, o que propicia produção e introdução de tecnologias ambientais. Assim, as indústrias passam a fazer parte de um ambiente mimético proativo, o que ajuda a intensificar a homogeneidade das tecnologias ambientais. As informações descobertas apontam, entretanto, para uma proatividade ambiental parcial das indústrias, visto que no Paraná esteve restrita a poucas e concentradas indústrias, o que reproduz estudos em outros Estados.

É evidente que a análise exclusiva das indústrias e do Estado não representou a totalidade do ambiente institucional que influencia a internalização ambiental das indústrias paranaenses, nem mesmo este artigo teve a intenção de encerrar a discussão. Todavia, o Estado, entendido como fomentador e executor de políticas ambientais, tem sido por décadas o agente mais importante para a implementação de práticas ambientais pelas indústrias. Até mesmo quando restringida sua capacidade de atuação coercitiva, outras formas de ação e não ação se tornam relevantes, haja vista os instrumentos econômicos e o modelo de política neoliberal. De toda forma, as indústrias em geral tendem a se direcionar ambientalmente através das orientações do Estado, sendo imprescindível o estudo de suas movimentações institucionais para a compreensão da internalização do meio ambiente nas indústrias, principalmente no Estado do Paraná, onde existe uma tradição na preservação do 
meio ambiente atrelada a atrasos no processo de industrialização do Estado.

Questionamentos para futuras pesquisas poderiam aprofundar, em formato de comparação, a eficácia dos instrumentos de comando e controle com os instrumentos econômicos quando relacionados à internalização ambiental nas indústrias paranaenses. Também poderia ser clarificada a proposta de internalização ambiental nas pequenas e médias indústrias pertencentes a arranjos produtivos locais no Paraná.

O enraizamento em ambientes sociais e políticos das estruturas organizacionais, como propõem os neoins-

\section{Referências}

ABEMA. Associação Brasileira de Entidades de Meio Ambiente. Diagnóstico institucional dos órgãos estaduais de meio ambiente no Brasil. Vitória/ES: Associação Brasileira de Entidades de Meio Ambiente, 1993.

ALPERSTEDT, G.; QUINTELLA, R.; SOUZA, L. Estratégias de Gestão Ambiental e seus fatores determinantes: uma análise institucional. Revista de Administração de Empresas (RAE), São Paulo, v. 50, n. 2, p. 710-186, 2010.

AMES, B.; KECK, M. E. The Politics of Sustainable Development: Environmental Policy Making in Four Brazilian State. Journal of Interamerican Studies and World Affairs, Florida, v. 39, n. 4, p. 1-40, 1997.

ARQUIVO PÚBLICO DO PARANÁ. Mensagens do Governo à Assembleia Legislativa de 1971 a 2006. Disponível em: <http://www.arquivopublico.pr.gov.br>. Acesso em: $12 / 12 / 2011$.

BALTAR, R. A reconstrução do discurso sobre o "Brasil Moderno" e a ideia de "desenvolvimento" pós-transição democrática. In: CHAIA, V.; MACHADO, E. (Org.). Ciências Sociais na atualidade: tempo perspectiva. São Paulo: Paulus, 2009.

BORINELLI, B. A institucionalização da gestão ambiental nas empresas e no Governo do Estado do Paraná: etapas, contextos e padrões de relações no período de 1970 a 2006. Grupo de Pesquisa em Política e Gestão Socioambiental. Londrina-PR: Universidade Estadual de Londrina - UEL, 2010.

BRASIL. Ministério do Meio Ambiente. Programa Nacional do Meio Ambiente II /PNMA 2. Diagnóstico da Gestão Ambiental no Brasil. Brasília, 2001. titucionalistas, pode ter sido uma resposta às mudanças na forma de internalizar as questões ambientais nas indústrias paranaenses, entre os anos de 1970 e 2006. Entretanto, a construção social das práticas organizacionais não parece direcionar as práticas de todas as indústrias paranaenses. Como mostrado no corpo do trabalho, ainda são poucas as indústrias que se apresentam na fase proativa de internalização ambiental. Aliados a essa baixa adesão industrial, os números ambientais do Paraná não se apresentam favoráveis, principalmente os relacionados a desmatamento e poluição hídrica.

BUSTAMANTE, M. I.; TORRES, S. Elementos para uma política ambiental eficaz. Revista de la CEPAL, Nações Unidas, n. 41, p.109-122, 1990.

CETSAM. Escola Técnica de Saneamento Básico e Ambiental. Indústrias e Meio Ambiente no Paraná. Curitiba: SENAI, 1997.

CORAZZA, R. I. Gestão ambiental e mudança na estrutura organizacional. Revista de Administração de Empresas (RAE), São Paulo, v. 2, n. 2, p. 1-23, 2003.

CUNHA, A. C. O homem papel: análise histórica do trabalhador das Indústrias Klabin do Paraná de Celulose S/A - 19421980. 1982. Dissertação (Mestrado em História Econômica) - Universidade Federal do Paraná, Curitiba, 1982.

DEMAJOROVIC, J.; SILVA, A. V. Arranjos produtivos locais e práticas de gestão socioambiental: uma análise do polo moveleiro de Arapongas. Ambiente e Sociedade, Campinas, v. 13, n. 1, p. 131-149, 2010.

DIMAGGIO, P. J.; POWELL, W. W. The Iron Cage Revisited: Institutional Isomorphism and Collective Rationality in Organizations Fields. American Sociological Review, USA, v. 48, p. 147-160, 1983.

EXPRESSÃO ECOLOGIA. Prêmio Expressão de Ecologia 10 anos: a onda verde no Sul. Florianópolis, 2002.

FERNANDEZ-ALLES, M. L.; VALLE-CABRERA, R. Reconciling Institutional Theory With Organizational Theories How Neoinstitutionalism Resolves Five Paradoxes. Journal of Organizational Change Management, London, v. 19, n. 4, p. 503-517, 2006. 
FERRAZ, C.; MOTTA, R. S. Regulação, mercado ou pressão social? Os determinantes do investimento ambiental na indústria. Texto para Discussão no 863. Rio de Janeiro: IPEA, 2002.

FIEP. Federação das Indústrias do Estado do Paraná. Memória da indústria paranaense. Curitiba, 2007.

FIEP 65 anos de história. Edição comemorativa.

Curitiba: Literal Link, 2009.

HOFFMAN, A. J. Linking Organizational and Field-Level Analyses: The Diffusion of Corporate Environmental Practice. Organization and Environmental, London, v. 14, n. 2, p. 133-156, 2001.

INMETRO. Instituto Nacional de Metrologia, Normatização e Qualidade Industrial. Disponível em: <www.inmetro.gov.br >. Acesso em: 15/03/2010.

IAP. Instituto Ambiental do Paraná. Legislação ambiental. Disponível em: $<$ http://www.iap.pr.gov.br/modules/conteudo/ conteudo.php? conteudo=276>. Acesso em: 20/07/2010.

IPARDES. Fundação Instituto Paranaense de Desenvolvimento Econômico e Social. Participação do setor público na economia paranaense, Relatório de Pesquisa $n^{\circ} 1$ : dimensão e estrutura da receita e despesa do setor público estadual. Curitiba: IPARDES, 1980.

Série retrospectiva do Paraná: Atlas Histórico da Indústria (1940/1980). Curitiba: IPARDES, 1993.

Crescimento, reestruturação e competitividade in-

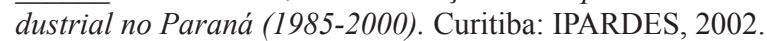

. Arranjos produtivos locais e o novo padrão de especialização regional da indústria paranaense na década de 90. Curitiba: IPARDES, 2003.

Mapas - base fisica, ambiental, econômica e social. Disponível em: $<\mathrm{http}: / / w w w . i p a r d e s . p r . g o v . b r />$. Acesso em: 05/01/2011.

JABBOUR, C. J. C.; SANTOS, F. C. A. The Evolution of Environmental Management Within Organizations: Toward a Common Taxonomy. Environmental Quality Management, v. 16, n. 2, 2006.

KLABIN. A unidade Monte Alegre. Telêmaco Borba: Klabin, 2011.

LOPES, C. R. A. Análise da indústria de papel e celulose no Brasil. 1998. Dissertação (Mestrado em Negócios) - Universidade Federal do Rio de Janeiro, Rio de Janeiro/RJ, 1998.
MEYER, J. W; ROWAN, B. Institutionalized Organizations: Formal Structure as Myth and Ceremony. The American Journal of Sociology, London, v. 83, n. 2, 1977.

MIGLIORINI, S. M. S. Indústria paranaense: formação, transformação econômica a partir da década de 1960 e distribuição espacial da indústria no início do século XXI. Geografar, Curitiba, v.1, n. 1, 2006.

MMA. Ministério do Meio Ambiente. Diagnóstico da gestão ambiental nas unidades da Federação: Relatório final. Estado do Paraná. Brasília, 2001.

MONOSOWSKI, E. Políticas ambientais e desenvolvimento no Brasil. Cadernos FUNDAP, São Paulo, v. 9, n. 16, p. 1524, jun. 1989.

NOJIMA, D. Crescimento e reestruturação industrial no Paraná - 1985/2000. Revista Paranaense de Desenvolvimento, Curitiba, n. 103, p. 23-43, 2002.

PADIS, P. C. Formação de uma economia periférica: o caso do Paraná. Curitiba: IPARDES, 2006.

POWELL, W. W. The New Institucionalism. The International Encyclopedia of Organization Studies. Sage Publishers, 2007.

SANCHES, C. S. Gestão ambiental proativa. Revista de Administração de Empresas (RAE), São Paulo, v. 40, n. 1, p. 76-87, 2000.

SEIN. Secretaria do Estado e Interior. Quatro anos de realizações (1975 - 1978): recursos hídricos e meio ambiente. Curitiba: Secretaria de Estado e Interior, 1979.

SONDA, C. Reforma agrária, desmatamento e conservação da biodiversidade no Estado do Paraná. In: SONDA, Claudia; TRAUCZYNSKI, Silvia Cristina (Orgs.). Reforma agrária e meio ambiente: teoria e prática no Estado do Paraná. Curitiba: ITCG, 2010.

SOUZA, R. S. Entendendo a questão ambiental: temas de economia, política e gestão do meio ambiente. Santa Cruz do Sul: EDUNISC, 2000.

. Fatores de formação e desenvolvimento das estratégias ambientais nas empresas. 2004. Tese (Doutorado) - Programa de Pós-Graduação em Administração, Universidade Federal do Rio Grande do Sul, Porto Alegre, 2004.

STN. Secretaria do Tesouro Nacional. Execução orçamentária dos Estados (1995 - 2010). Disponível em: <http://www.stn. gov.br/estados_municipios/index.asp>. Acesso em: dez. 2011. 
SUREHMA. Superintendência de Recursos Hídricos e Meio Ambiente. Problemática ambiental do Estado do Paraná. Curitiba: Superintendência de Recursos Hídricos e Meio Ambiente, 1979.

Relatório de atividades da SUREHMA - 1987/1990.

Curitiba: Superintendência de Recursos Hídricos e Meio Ambiente, 1990.

TRIBUNAL DE CONTAS DO ESTADO DO PARANÁ. Relação de pagamentos de compras e de serviços efetuados ao Instituto Ambiental do Paraná-IAP (2004-2010). Disponível em: <http://www.gestaodinheiropublico.pr.gov.br/Gestao/ gastos/ConsultaPagamentos.jsp>. Acesso em: 06/12/2011.
TRIGUEIRO, A. (Coord.). Meio ambiente no século 21: 21 especialistas falam da questão ambiental nas suas áreas de conhecimento. Campinas: Armazém do Ipê, 2008.

WACHHOLZ, F. D. Barômetro de gestão ambiental em empresas do Estado do Paraná-Brasil. 2004. Tese (Doutorado) - Programa de Pós-Graduação em Engenharia Ambiental, Universidade Regional de Blumenau, Blumenau, 2004.

ZAPPAROLI, I. D.; CÂMARA, M. G. Polo moveleiro de Arapongas - PR: relação entre a tributação e a postura ambiental das indústrias de móveis. In: ENCONTRO DA SOCIEDADE BRASILEIRA DE ECONOMIA, 47., 2009. Anais... Porto Alegre, 2009.

Recebido em 10 de setembro de 2012. Aceito em 20 de fevereiro de 2013. Publicado em junho de 2013. 